\title{
O DESIGN E A TÉCNICA: TRANSFORMANDO FATOS INCONTESTÁVEIS EM QUESTÕES DE PONDERAÇÃO
}

Luciana Ponce da Motta Keller

Universidade Federal do Rio de Janeiro

keller.luciana@gmail.com

Jorge Lucio de Campos, Dr.

ESDI - Universidade do Estado do Rio de Janeiro

Resumo: Este artigo apresenta um breve paralelo traçado entre dois autores Pierre Lévy e Bruno Latour - com a finalidade de levantar algumas considerações destinadas especificamente à área do Design. Nele se argumenta que estes dois pensamentos convergem de forma complementar para a discussão da apropriação coletiva da técnica, bem como em relação à importância do design para a sociedade, tecendo questões que concernem ao fazer humano como um todo. À luz de suas ideias, são delineadas proposições a respeito da importância do papel do designer no fazer coletivo, juntamente com a exigência de uma prudência moral por parte do profissional de design, ao pensar a técnica como uma ação política em um cenário social. Nele é também destacada a importância da compreensão, por parte do designer, do objeto de design como um campo de disputa de forças, onde se materializam, por meio da técnica, diferentes perspectivas socioculturais, com diferentes usos e interpretações possíveis. São igualmente abordados alguns de seus conceitos chaves, em especial, os conceitos de matter of facts e matters of concern, para os quais se propõe uma tradução.

Palavras-chave: design, técnica, matters of concern, groupware

Abstract: This paper presents a brief parallel between two authors - Pierre Lévy and Bruno Latour - in order to raise some considerations aiming specifically at the Design area. It is argued that these two thoughts converge in a complementary way to the discussion of collective technical ownership as well as on the importance of design for society, weaving issues that concern the human doing as a whole. Through those ideas, proposals are outlined around the importance of the designer's role in collaborative making, along with the need for a moral caution by the design professional, conceiving the technique as a political action in a social setting. It also highlights the importance of the designer understanding of the design object as a result of multiple forces influences, which is materialized through the technique, different sociocultural perspectives, with different uses and possible interpretations. There is also addressed some of his key concepts, in particular the concepts of matter of facts and matters of concern, for which it is proposed a translation. 
Keywords: design, technique, matters of concern, groupware

\section{INTRODUÇÃO}

O presente trabalho visa abordar a temática do fazer humano sobre o mundo a partir das perspectivas dos pensadores franceses Bruno Latour (n. 1947) e Pierre Lévy (n. 1956), delineando uma discussão pertinente à área do design mediante o conceito de técnica. Cria-se aqui um paralelo entre as perspectivas apresentadas por estes, na crença de que, apesar de seus diferentes enfoques, ambos tratam do assunto de forma semelhante e complementar. Estes autores abordam questionamentos relevantes não apenas ao design, mas também a todas as formas de conhecimento que lidam com o fazer humano, a produção e a criação. Pondo-os em diálogo, busca-se compreender as proximidades entre suas obras, bem com ilustrar diferentes perspectivas acerca da projetação humana consciente em sociedade, ressaltando a importância do designer enquanto agente político.

Lévy (1993) discorre sobre as dimensões políticas e culturais da técnica (tratando igualmente a escrita, a matemática, o livro e o computador como tal) e argumentando em prol dos usos potenciais das novas tecnologias. Já Latour (1994) discute a transição dos matter of facts, verdades absolutas e inquestionáveis (as quais serão traduzidas daqui em diante como "fatos incontestáveis"), para os matters of concern, questões complexas e que não podem ser divididas ou delimitadas exclusivamente a uma área (aqui nomeadas como "questões de ponderação").

Ambos delineiam um interesse comum: a compreensão das múltiplas dimensões (culturais, politicas, econômicas, históricas, religiosas, etc.) que tangem o fazer humano. Para eles, através da compreensão destas múltiplas dimensões da técnica, abre-se uma nova "categoria" de análise, mais ampla e completa, essencial ao designer focado nos reais interesses do usuário.

Entende-se aqui, a técnica por meio dos conceitos apresentados por Lévy, como a aplicação do fazer humano sobre o mundo. Em sua conceituação, todo produto humano possui uma dimensão técnica, que compreende não apenas o "como" aquele objeto foi produzido, mas também os "porquês" e os significados nele contidos. Para ele, apesar da técnica e as tecnologias serem amplamente discutidas, ainda são objeto de muitos preconceitos, estando associadas por alguns a uma imagem potencialmente cruel, inelutável e catastrófica.

Sua ótica em relação à técnica é, por outro lado, otimista, ressaltando seu potencial benéfico e construtivo. Nesse sentido, a tecnologia é capaz de estruturar a experiência do indivíduo, influenciando diretamente no modo como o mundo e os objetos são por ele percebidos.

\section{OS OBJETOS DE DESIGN A PARTIR DO CONCEITO DE TÉCNICA}

No livro As tecnologias da inteligência, Lévy discute profundamente as dimensões do que chama de técnica. Para o autor, o conceito seria a manifestação da ação humana consciente sobre a natureza e a sociedade. A técnica seria o próprio fazer humano e, como tal, estaria sujeita às questões do "para que", do "porquê" e do "como" fazer. Teríamos, ao longo do tempo, desenvolvido e adotado diferentes técnicas para lidar com situações adversas, simplificar as dificuldades cotidianas ou simplesmente interagir com o mundo. 
Nesse sentido, a tecnologia e os meios de comunicação são, por exemplo, manifestações técnicas das ações humanas. Portanto surgem, historicamente, novas tecnologias e meios de comunicação dos quais nos apropriamos. Entretanto, para diferentes povos e em diferentes momentos históricos, essa apropriação se dá de modos bem distintos. Dentro dessa concepção, as referidas questões do "para que", do "porquê" e do "como", que direcionam a técnica, nem sempre são as mesmas.

A técnica é uma manifestação social e, como tal, dotada de dimensões culturais, políticas, históricas e simbólicas. Contudo, existem perspectivas que defendem a sua neutralidade política e moral, como por exemplo: o positivismo nas ciências; a ideia de progresso presente em muitos discursos políticos; ou mesmo o surgimento de organizações internacionais (ONU, UNESCO, Banco Mundial, etc.) que desenvolvem políticas e metas globais para um suposto desenvolvimento econômico e social global. Como afirma o autor: "A técnica em geral, não é nem boa, nem má, nem neutra, nem necessária, nem invencível. É uma dimensão recortada pela mente de um devir coletivo heterogêneo e complexo na cidade do mundo" (LÉVY, 1993, p. 196).

Sendo assim, supor a técnica, ou qualquer outra dimensão de análise como orientada por um juízo de valor, digamos, como algo neutro, bom ou mal, seria sujeitar-se a uma concepção errônea do objeto de análise. Uma vez que tanto a técnica quanto o ser humano são arbitrários, os objetos criados também compartilham desta arbitrariedade. Isso porque as escolhas por trás das criações humanas (suas características físicas, aplicação de materiais, ornamentação, opções cromáticas, etc.) não são "dadas", nem são absolutas em sua função, portanto não partem de uma neutralidade, mas de uma análise, de uma ação e de uma reflexão conscientes.

A consciência de que a técnica é apenas uma dimensão de análise, sendo, por esta razão, arbitrária, deve se refletir na concepção do designer em relação ao seu objeto de estudo, seja este um produto material, gráfico, digital, ou qualquer outro. Compreendendo que seu objeto não pode ser analisado enquanto um "dado", mas enquanto uma manifestação social (derivado de múltiplas dimensões culturais, políticas e históricas), o profissional é capaz de evitar, ou ao menos problematizar, o que Lévy descreve com perigo da abstração da técnica: uma pretenciosa abstração (no sentido de "tornar algo abstrato"), que isola a técnica de suas dimensões sociais e busca promovê-la como um conhecimento autônomo, neutro e infalível. $\mathrm{Na}$ perspectiva do autor, este é um grande impedimento para que se alcance certa democracia sob a técnica (tecnodemocracia), qual seja, um movimento plural e público de discussão, reflexão e concepção da técnica, enquanto um produto social.

Mesmo não tendo a pretensão de tornar cada objeto projetado em um objeto político, ao pensar a técnica como ação política em um cenário social, o designer pode percebê-lo enquanto um campo de disputa, onde diferentes entidades, à frente de diferentes projetos de sociedade, terão diferentes usos e interpretações de um mesmo elemento técnico. Sob esse viés, o positivismo e o progresso nada mais seriam do que perspectivas políticas em disputa por legitimidade e a frente de certo projeto de sociedade. O designer, por sua vez, também possui perspectivas políticas que se refletirão inconscientemente em suas criações. Essas perspectivas, entretanto, podem não ser condizentes com as do usuário final ou mesmo com as das entidades envolvidas no processo de produção, distribuição e venda.

Lévy problematiza recorrentemente a falta de compreensão das dimensões políticas, históricas e culturais da técnica, enfatizando a necessidade da compreensão 
de seu contexto de emprego. Um exemplo trazido pelo autor é um caso de informatização das escolas na França que, sob sua ótica, fracassou devido à compreensão errônea de que a técnica, no caso, a informática como tecnologia da informação, seria autônoma e autossuficiente.

Entendendo a informática como uma entidade autônoma, ou seja, independente do fazer, o que se fez foi levar computadores até as escolas e montar laboratórios, acreditando que sua mera presença seria o suficiente para melhorar o processo educativo. Não se pensou em realizar, por exemplo, uma formação dos professores para que trabalhassem com o novo material; ou mesmo na confecção de softwares educativos adequados a determinados modelos de trabalho e a distintas perspectivas pedagógicas. Isso porque se tinha a ideia de que a tecnologia seria, por si só, se adequar às ou revolucionar as práticas escolares.

Para Lévy, as autoridades à frente da informatização das escolas consideraram o contexto da aplicação desta técnica (no caso, o computador), como um simples "detalhe" do projeto. Com isso, ignorou-se que, nas palavras do autor, "estratégias vitoriosas passam pelos mínimos detalhes 'técnicos', dos quais nenhum pode ser desprezado, e que são todos inseparavelmente políticos e culturais, ao mesmo tempo em que são técnicos" (LÉVY, 1993, p. 9). Dessa forma, o autor busca evidenciar como as tecnologias que parecem ser autônomas (como os computadores, celulares e gadgets tecnológicos) ou apenas de dimensão técnica são, em realidade, tão plurais quanto o contexto que as cerca e os indivíduos que as manipulam.

Trazendo essa comparação para o design, acreditar na técnica enquanto algo autônomo, seria o mesmo que afirmar que um produto por si só seria suficiente para revolucionar uma sociedade que não o conhecesse. Por outro lado, defender a pluralidade técnica também significa afirmar que, do mais banal dos utensílios de cozinha ao mais complexo dos instrumentos cirúrgicos, as produções humanas não são neutras, nem autônomas, mas apenas técnicas, ou seja, manifestações da ação humana consciente sobre a natureza e a sociedade, sujeitas, como já dito, às questões do "para que", do "porquê" e do "como" fazer.

Essa pluralidade evidente nos objetos físicos é atribuída à própria complexidade humana. Uma vez que o homem não pode ser visto exclusivamente por uma única lente, ou seja, que não se pode compreendê-lo em sua totalidade a partir de apenas um de seus aspectos (o econômico, o religioso, o histórico, etc.), a técnica, que é, em última instância, a ação ou intervenção humana sobre o mundo, também não pode ser compreendida apenas por uma dessas dimensões. Sob essa perspectiva, cada objeto de design deve ser interpretado como o resultado de múltiplas influências, incluindo igualmente as sensoriais, as políticas, as ergonômicas, as culturais, etc.

Como afirma Lévy, a apropriação da técnica pelo homem também passa por sua percepção do mundo, sendo, por tanto, influenciada por seu contexto. Consequentemente, não existe um conhecimento técnico abstrato ou isolado, que não exija questionamento ou reflexão em seu desenvolvimento e em sua apropriação social. Esses conhecimentos, reafirmamos, são orientados por perspectivas políticas, históricas e culturais, mesmo que esta orientação não ocorra de modo consciente.

Em outras palavras, o reconhecimento da pluralidade de dimensões da técnica e, em especial, na construção do conhecimento técnico, permite uma clareza social acerca das políticas que orientam as ações e decisões a serem tomadas coletivamente. Em oposição, está o perigo da abstração do conhecimento, onde, segundo o autor, se tem 
uma visão reducionista do mundo, na medida em que se estimula a percepção de que este é dirigido por forças sempre transcendentais ao indivíduo (entidades transhistóricas). Segundo ele:

\begin{abstract}
A ciência e a técnica representam uma questão política e cultural excessivamente importante para serem deixadas a cargo dos irmãos inimigos (cientistas ou críticos da ciência) que concordam em ver no objeto de seus louvores ou de suas censuras um fenômeno estranho ao funcionamento social ordinário. [...] Não existe uma "Técnica" por trás da técnica, nem um "Sistema Técnico" sob o movimento da indústria, mas apenas indivíduos concretos situáveis e datáveis. [...] Essas vagas entidades trans-históricas, estes pseudoatores são, na realidade, desprovidos de qualquer eficácia e não apresentam simetricamente qualquer ponto de contato para a mínima ação real. Frente a estas abstrações, evidentemente ninguém pode negociar nem lutar. (LÉVY, 1993, p. 12-3)
\end{abstract}

Entretanto, diz Lévy, deve-se ter em mente que a abstração do conhecimento e, consequentemente, seu isolamento do contexto social é normal e, por vezes, necessário para o estudo científico. A abstração é apenas um recurso de análise e não mais do que isso, devendo ser superada por aquele que analisa, uma vez que no recorte são descartadas várias das dimensões presentes no objeto, não sendo possível, portanto, compreendê-lo como um todo. Para o pensador francês, ao analisar um objeto de design - que é também técnico, arbitrário e influenciado profundamente por seu contexto - a abstração deste objeto pode ser adotada para fins pedagógicos ou para a simplificação de determinado raciocínio a seu respeito, desde que o pesquisador (no caso, o designer) compreenda que a sua natureza multifacetada jamais poderá ser captada através de uma única dimensão de análise. Do mesmo modo, é necessário ao designer compreender que, por mais sofisticado que seja seu projeto, ele não irá, por si só, revolucionar uma situação ou condição.

\title{
3. AS QUESTÕES DE PONDERAÇÃO NO DESIGN
}

No ensaio A cautious Prometheus? A few steps toward a philosophy of design ${ }^{1}$ (LATOUR, 2008), Latour nos lembra que o termo design tem crescido em compreensão e significado. Ou seja, não apenas ele compreende mais elementos - com o verbo to design podendo se referir igualmente a "planejar", "calcular", "definir", "projetar", "escrever em código", etc - como também passou a possuir uma significação mais ampla, sendo aplicável a uma gama cada vez maior de produtos, não mais se restringindo a bens industriais ou de luxo. Desse modo, abrangendo uma gama conceitual mais vasta e diversificada, os limites do termo "design" gradativamente se dissolvem, levantando questões que tangem, cada vez, a mais áreas.

Latour (2008) afirma que seu interesse pela expansão do termo design, surge a partir da metáfora que esta nos traz frente à mudança na maneira pela qual nos relacionamos com os objetos. Para explicá-la, recorre a dois conceitos anteriormente

\footnotetext{
${ }^{1}$ Em português: "Um Prometheus cauteloso? Alguns passos em direção à Filosofia do Design".
} 
cunhados por ele próprio: matters of fact, expressão que aqui será traduzida ${ }^{2}$ como "fatos incontestáveis"; e matters of concern, como "questões de ponderação".

Ambos os conceitos são apresentados na obra Jamais fomos modernos ${ }^{3}$ (LATOUR, 1994), através do exemplo das disputas entre dois destacados personagens históricos do século XVII: Robert Boyle e Thomas Hobbes. O autor nos mostra como estes pensadores contribuíram para a construção do pensamento científico e da concepção atual de ciência. Apesar de suas divergências, buscaram a formulação de fatos incontestáveis que regem as leis tanto dos corpos físicos quanto da sociedade.

Através de suas experiências com a bomba de vácuo em laboratório, Boyle cria - estilo empírico de pesquisa: "funda-se sobre uma metáfora parajurídica: testemunhas [...] reunidas em torno da cena da ação podem atestar a existência de um fato, the matter of fact, mesmo se não conhecerem sua verdadeira natureza" (LATOUR, 1994). A partir desta perspectiva de formulação de fatos científicos comprovados através da experiência, é que se iniciaram as disputas entre Boyle e Hobbes, especialmente em relação à mudança de escala dos experimentos e à sua aplicabilidade para questões sociais. Neste momento de disputa, cria-se também uma serie de demarcações e divisões entre essas perspectivas.

Consequentemente, essas divisões enraizadas na concepção de ciência se apresentam hoje de modo natural, como se fossem inatas à ciência. A fragmentação do conhecimento científico através de inúmeras disciplinas é uma das marcas de tais disputas. Contudo, Latour (1994) defende, assim como Lévy, que estas separações sejam apenas dimensões de análise, uma vez que não são limites reais, mas traçados através de um contexto histórico. Em relação a essa divisibilidade, o autor afirma:

A palavra "moderno" designa dois conjuntos de práticas totalmente diferentes que, para permanecerem eficazes, devem permanecer distintas, mas que recentemente deixaram de sê-lo. 0 primeiro conjunto de práticas cria, por "tradução", misturas entre gêneros de seres completamente novos, híbridos de natureza e cultura. O segundo cria, por "purificação", duas zonas ontológicas inteiramente distintas, a dos humanos, de um lado, e a dos não-humanos, de outro. [...] O primeiro conjunto corresponde aquilo que chamei de redes, o segundo ao que chamei de crítica. [...] Enquanto considerarmos separadamente estas práticas, seremos realmente modernos, ou seja, estaremos aderindo sinceramente ao projeto da purificação crítica, ainda que este se desenvolva somente através da proliferação dos híbridos. (LATOUR, 1994, p. 16)

Desse modo, o autor defende sua tese de que "jamais fomos modernos", apontando para a divisibilidade forçada que criamos entre natureza e cultura, característica dos "modernos", no sentido de que esta cisão nunca foi aceita como um fato incontestável. Para Latour (1994), a perspectiva criada por essa divisibilidade forçada, na qual é buscada uma setorização do conhecimento, se faz contraditória,

\footnotetext{
${ }^{2}$ Mesmo tendo conhecimento da profundidade de significação dos termos, sentiu-se nesta explicação a necessidade de sua tradução, a fim de facilitar a compreensão do texto, em especial, para aqueles não familiarizados com o autor.

${ }^{3}$ A palavra "moderno", nesse contexto, se refere à Idade Moderna e não ao movimento modernista.
} 
uma vez que os objetos de estudo da ciência não podem, de fato, ser divididos e "purificados", através de uma lente única.

Latour define como híbridas estas questões complexas. Em um exemplo rápido, ele simula a leitura das páginas de um jornal, em que, apesar das notícias estarem separadas por setores, seu conteúdo é cada vez menos divisível e cada vez mais híbrido: "o menor vírus da AIDS nos faz passar do sexo ao inconsciente, a África, as culturas de células, ao DNA, a São Francisco" (LATOUR, 1994, p.8).

De modo semelhante, ao compreender o objeto como híbrido, o designer liberta-se dessas divisões. Seu objeto não mais pertence a uma categoria fechada, deixando de ser econômico, político, recreativo, etc. Sob a perspectiva de projetar uma coisa híbrida (nos termos do autor), o designer é, então, capaz de adotar abordagens transversais em sua análise do produto, e passa a ser igualmente capaz de adotar ideias advindas de outras áreas, bem como de outros profissionais. $O$ designer torna-se, então, gradativamente mais flexível à diversidade de questões que compõem seu objeto de estudo.

Para Latour (1994), a indivisibilidade crescente do modo como percebemos o mundo, conectando um assunto a outro - em forma de rede, e não mais através da separação ou de classificações rígidas - é a transição dos fatos incontestáveis, citados anteriormente, para as questões de ponderação. Essa mudança se reflete, portanto, no próprio pensamento científico, que não mais se ocupa em formular fatos incontestáveis, mas em buscar uma variedade de possíveis soluções para questões de ponderação complexas e plurais. Segundo o autor:

Se for verdade, como afirmei, que nós jamais fomos modernos e, consequentemente, ainda for verdade que "fatos incontestáveis" claramente se tornaram "questões de ponderação", então, há lógica na seguinte observação: [...] Quanto mais objetos são transformados em coisas $^{4}$ - isto é, quanto mais fatos incontestáveis são transformados em questões de ponderação - mais eles são representados como objetos de design. ${ }^{5}$ (LATOUR, 2008, p. 2)

Para o autor, quanto mais os fatos incontestáveis são transformados em questões de ponderação, mais os objetos são representados como objetos de design (LATOUR, 2008). Ou seja, quanto mais projetamos os elementos que compõem o mundo ao nosso redor no sentido amplo do termo "design" descrito pelo autor, mais tornamos plurais (e materiais) as questões que antes eram simplificadas, tomadas por uma única dimensão abstrata.

Sob esta ótica, o design se apresenta como um meio particularmente propício para se trabalhar com problemas transversais, abordados por diversas dimensões, como defende Lévy, além de configurar um meio potencial para se materializar soluções para tais problemas:

Pensar em artefatos, em termos de design, significa concebe-los cada vez menos como objetos modernistas, e concebe-los cada vez mais como "coisas". Em meus termos, artefatos estão sendo concebidos

\footnotetext{
${ }^{4} \mathrm{O}$ termo "coisas", para o autor, é diretamente relacionado às questões de ponderação, referindo-se a uma categoria mais ampla do que a do termo "objeto", relacionado aos fatos incontestáveis.

${ }^{5}$ Tradução própria.
} 
como uma complexa união de questões contraditórias [...]. Quando as coisas são tomadas como tendo sido bem ou mal projetadas, elas não aparentam mais ser como os fatos incontestáveis. Então, quanto mais as coisas enfraquecem enquanto fatos incontestáveis, seu lugar entre as questões de ponderação se fortalece. (LATOUR, 2008, p.4)

Latour (2008) identifica o exercício da atividade do design em todos os profissionais que lidam com essa transformação das coisas, tanto em escala micro, quanto macro. Essa ação do homem sobre o mundo não se restringe aos profissionais de design. Para ele, a extensão do design se deu de tal forma que não há mais nada que não seja projetado (designed): das cidades aos genes; assim como a natureza, que não é (ou não deveria ser) mais encarada com exterior ao homem, uma vez que está sujeita à manipulação humana. $O$ autor ressalta que essa expansão traz consigo um senso de moralidade ao design:

A difusão do design à definição interna das coisas carrega consigo, não apenas significado e hermenêutica, mas também moralidade. Mais precisamente, é como se materialidade e moralidade estivessem finalmente se fundindo. Isto é de grande importância porque, se você começa a reprojetar as cidades, as paisagens, os parques naturais, as sociedades, bem como os genes, o cérebro e os chips de computador, a nenhum designer será permitido se esconder atrás da antiga proteção dos fatos incontestáveis. Nenhum designer será capaz de afirmar: "Vou apenas continuar com o que já existe", ou "Estou simplesmente esboçando as consequências das leis da natureza", ou "Estou apenas aceitando o resultado". Ao expandir o design até que este se tornasse relevante por toda parte, os designers também pegam para si o manto da moralidade (LATOUR, 2008, p. 5-6).

Essa noção de moralidade contida na atividade de projeto, juntamente com a noção de que outros profissionais se somam ao profissional de design para projetar o mundo em conjunto, tanto permite ao designer compartilhar suas perspectivas quanto o obriga a fazê-lo. Após entender que seu produto será inserido em um contexto que também possui uma dimensão política e que, em função disso, estará sujeito à moral humana, o designer não mais poderá ignorar as consequências do impacto causado por suas produções.

Latour (2008) identifica no design uma espécie de inconformismo com o mundo, uma recusa pelo existente em busca de um aprimoramento dos detalhes. Para autor, a atenção aos detalhes está intimamente ligada ao jeito do design. De modo semelhante, como citado anteriormente, Lévy atribui um senso de moralidade à preocupação com os detalhes, pois, através deles, o designer se distancia do perigo da abstração, buscando compreender as diversas dimensões que compõe uma mesma questão em um objeto.

Esta questão é apresentada de forma provocativa por Latour (2008), ao afirmar que design é um dos termos que substituiu a palavra "revolução". O autor discerne dois "modos" do fazer: o jeito antigo, atribuído por ele à ideia de criação e aos modernistas; e o jeito do design. O primeiro remete à sucessão descontinuada de ideias e valores, rompendo radicalmente com o passado em prol do futuro, 
rompimento este característico do modernismo. Já o segundo é o exato oposto. Em vez de descartar o que já existe, o jeito do design sempre parte daquilo que lhe é dado, buscando, a partir dos detalhes, reformular o mundo, aos poucos e sucessivamente. $\mathrm{Na}$ perspectiva de Latour, o design tem como virtude a capacidade de considerar e valorizar o contexto para, então, partindo dele, modificar, em vez de rejeitar, o já existente e gerar algo "do zero". Ainda que criar algo a partir do nada fosse de fato possível, ele se beneficiaria por reconhecer o valor do contexto para o projeto, além de dominar os meios para dele se apropriar.

Lévy também discorre a respeito desta sucessão continua de reformulação das coisas, apontada por Latour (2008) como uma característica do design. Para ele, as tecnologias (exemplificadas em sua obra pela oralidade, escrita, impressão e informática) não se sucedem de forma linear, como se uma fosse capaz de substituir a outra. Pelo contrário, uma tecnologia não é responsável por anular ou romper com a anterior, mas por potencializar o surgimento de novos agenciamentos de significado, bem como novos cenários e novas possibilidades de uso. Em relação à sucessividade das tecnologias, Lévy afirma que:

[...] a sucessão da oralidade, da escrita e da informática como modos fundamentais de gestão social do conhecimento não se dá por simples substituição, mas antes por complexificação e deslocamento de centros de gravidade. $O$ saber oral e os gêneros de conhecimento fundados sobre a escrita ainda existem, é claro, e sem dúvida irão continuar existindo sempre. [...] A progressão multiforme das tecnologias da mente e dos meios de comunicação pode ser interpretada como um processo metafísico molecular, distribuindo sem descanso as relações entre sujeitos individuais, objetivos e coletivos. (LÉVY, 1993, p. 10)

Para Lévy, toda tecnologia parte de um contexto necessariamente ligado às tecnologias que a precederam. Os objetos de design enquanto tecnologias podem, portanto, ser compreendidas como resultado da sucessão das técnicas que as precederam, sem necessariamente tornarem obsoletas suas predecessoras, criando, porém, novas possibilidades para seus usuários.

Ao adotar essa concepção, o designer admite o potencial construtivo e transitório dos objetos de design, permitindo que sua produção seja compreendida em perspectiva com outras técnicas, e não como um fim em si mesmo. Desse modo, além de auxiliar no "combate" à visão reducionista imposta pela abstração da técnica, ele também se aproxima do ponto de vista do usuário, que jamais percebe o objeto de design como algo isolado, mas sim pertencente a um contexto, seja este criado pelo ambiente de aplicação do objeto ou por suas próprias experiências de vida.

\section{O DESIGNER E A TÉCNICA}

Latour (2008), ao identificar em diversas profissões o jeito do design, vai ao encontro dos pensamentos de Lévy. Mesmo sem se referir diretamente ao design ou aos designers, este último fala dos "futuros arquitetos cognitivos" imaginados por 
Douglas Engelbart ${ }^{6}$, que apresentam esta postura de preocupação com os detalhes, de compreensão plural das dimensões de seus projetos.

Esta categoria seria responsável por desenvolver as interfaces das máquinas, a fim de torná-las mais intuitivas e significativas para os usuários, facilitando assim tanto o diálogo entre o homem e a máquina, quanto o diálogo entre os próprios usuários. Os "arquitetos cognitivos" seriam responsáveis por auxiliar, através das tecnologias informáticas, o agenciamento de pessoas, por desenvolverem espaços (assim como os arquitetos de espaços físicos) que compreenderiam em profundidade as funções cognitivas humanas.

Segundo Lévy, esta função só é alcançável através do entendimento das dimensões políticas e sociais da técnica, ressaltando que estes futuros arquitetos de espaços virtuais não irão "construir novas cidades em campo aberto para indivíduos maleáveis e sem passado. Muito pelo contrário, deverão levar em conta particularidades sensoriais e intelectuais da espécie humana" (LÉVY, 1993, p.53). Nesta mesma descrição, o autor também esclarece que a transição para as "novas cidades (espaços)" deve se dar sem choques brutais e com a participação de todo os interessados, tornando-se o processo mais democrático.

Essa mesma descrição também é verdadeira para o designer que projeta artefatos físicos e materiais. Assim como os arquitetos de espaços virtuais, descritos por Lévy, esse designer também deve compreender as particularidades cognitivas, sensoriais e intelectuais dos usuários, bem como sua história e suas perspectivas.

Do mesmo modo que Latour (2008) afirma que o design nunca é um processo que se inicia a partir do nada, mas que todo design seja sempre um redesign, Lévy também identifica no processo de concepção das coisas, assim como no de resolução de problemas, a necessidade de se partir de algo que é dado, preexistente, opondo-se ao jeito antigo (ao modo da revolução):

Toda criação equivale a utilizar de maneira original elementos preexistentes. Todo uso criativo, ao descobrir novas possibilidades atinge o plano da criação. [...] Criação e uso são, na verdade, dimensões complementares de uma mesma operação elementar de conexão, com seus efeitos de reinterpretação e construção de novos significados. (LÉVY, 1993, p. 59)

Esse posicionamento em relação ao fazer das coisas é válido também para as perspectivas políticas da técnica, em especial para o uso coletivo da técnica. Lévy, ao citar Engelbart, introduz o conceito de groupware. Hoje estamos habituados com tecnologias que só fazem sentido se utilizadas coletivamente, como as redes social, os compartilhamentos de arquivos e as videoconferências pela internet. Na década de 1990, entretanto, muitas destas tecnologias eram apenas conceituais e, portanto, ainda não haviam sido disseminadas.

O groupware, na concepção de Lévy, é uma tecnologia que, assim como as citadas a cima, conecta pessoas, agenciando-as e permitindo que trabalhem coletivamente. Contudo, o conceito de groupware não se restringe a apenas essa

\footnotetext{
${ }^{6}$ Ex-diretor do Augmentation Research Center do Stanford Research Institute, pioneiro nas pesquisas com interfaces informáticas.
} 
caracterização, não apenas auxilia a concepção e a discussão coletiva, como também inaugura uma nova geometria de comunicação.

Em outras palavras, o groupware, que é, em última instância, uma plataforma para o trabalho coletivo, ao agenciar pessoas, permite uma nova forma de organização do trabalho. Os usuários situaram-se em uma discussão e, simultaneamente, conectam seus argumentos em rede, não mais valorizando o discurso de um único indivíduo.

Para Lévy, "não é 'mais cada um na sua vez' ou 'um depois do outro', mas sim uma espécie de lenta escrita coletiva, dessincronizada, desdramatizada, expandida [...] sempre disponível, ordenada e objetiva sobre a tela". Sendo assim, o groupware é um meio através do qual é possível o agenciamento do que o autor conceitua como inteligência coletiva, um saber dessincronizado, ubíquo e resultante.

O campo de atuação de softwares e plataformas de trabalho coletivo de fato evoluiu nas últimas décadas (PIMENTEL e FUKS, 2012). Contudo, como já citado, a aplicação de toda técnica, no caso, dos groupwares, também passa por questões culturais, históricas e politicas. Permitir ou facilitar um trabalho realmente colaborativo (no mesmo sentido utilizado em $\operatorname{CSCW}^{7}$ ), seguindo a conceituação de Lévy, perpassa pelas mesmas dificuldades observadas em ambientes reais de trabalho, como conflitos de interesse, dificuldade de diálogo e ideologias divergentes.

Nesse sentido, Latour (2008), por sua vez, vai um pouco além, trazendo a aplicabilidade política da técnica como questionamento central de sua fala aos estudantes de história do design. $\mathrm{O}$ autor alega que, apesar de intervirmos em todos os aspectos do mundo que nos cerca, de sermos capazes projetar das cidades aos genes humanos, ainda assim, "somos extremamente incapazes de fazer tudo isso em conjunto, de simular, de materializar, de aproximar, de modelar completamente em escala, o que uma coisa, em toda sua complexidade, é". (LATOUR, 2008, p. 13)

Com isso, o autor introduz o conceito de desenhar coisas juntos ${ }^{8}$, ou seja, de projetar (no sentido amplo do design) em conjunto, considerando todas as dimensões da aplicabilidade da técnica, além de incluir todos os envolvidos no processo. Latour (2008) afirma ainda que o que é necessário para desenhar coisas juntos são ferramentas que permitam visualizar as questões de ponderação, desconstruindo a visão modernista de tornar lineares e objetificadas as questões relativas ao design.

\section{CONSIDERAÇÕES FINAIS}

A indivisibilidade entre a técnica e suas questões político-sociais se relaciona diretamente com a opinião apresentada por ambos os autores, Lévy (1993) e Latour (1994 e 2008) no que tange o fazer das coisas e, por consequência, também ao design. A "provocação" levantada por Latour (2008, p. 13) a seus ouvintes, "porque somos incapazes de desenhar em conjunto?", também está em parte presente na discussão trazida por Lévy (1993) sobre a técnica. As ferramentas de visualização das questões de ponderação perpassam, necessariamente, pelo perigo da abstração defendido por Lévy (1993), uma vez que, a compreensão da pluralidade das questões de ponderação não pode ser alcançada através de um ponto de vista único.

Por esse motivo, em ambos os discursos, o design exerce um papel fundamental na materialização de questões diversas e disputas de força em objetos e

\footnotetext{
7 Sigla para Computer Suported Cooperative Work ("Trabalho Cooperativo Assistido por Computador").

${ }^{8}$ No original, "drawing things together".
} 
estruturas concretas, que influenciam a sociedade a partir de detalhes técnicos. Para Lévy, os arquitetos cognitivos - que são também designers no sentido amplo de Latour (2008) - serão os responsáveis por agenciar pessoas por meio da técnica. Segundo o autor, esse processo não se dará através de uma revolução tecnológica, mas sim mediante uma sucessão progressiva de pequenos ajustes, pequenos detalhes, que explorem todas as potencialidades que as tecnologias têm a oferecer.

Latour (2008) aponta as potencialidades do uso do design não apenas como um meio de materialização de soluções (de aplicação da técnica), mas como um meio de facilitar a visualização das questões sociais, morais, culturais e políticas que envolvem essa materialização. Nesse sentido, o designer se apresenta como um elo vital na potencialização dos usos tecnológicos, devido à sua intrínseca capacidade de visualização e de materialização das questões de ponderação por meio da técnica e de agenciar, através dela, pessoas e resolver questões complexas.

Para tanto, o designer deve superar uma perspectiva abstrata do conhecimento e da técnica, regida tanto pelo contexto de seu emprego, quanto pelo de sua produção. Sendo assim, o designer deve se apropriar destes conceitos, pô-los à prova a todo instante e mantê-los sob uma constante reflexão, pois, somente em contato com o mundo (em toda sua complexidade) será possível enxergar as potencialidades e limites do produto que está sendo desenvolvido.

Através dessa compreensão, se atingem as questões de ponderação, contemplando os impactos que a política e a cultura exercem sobre a técnica e viceversa. Somente a partir dessa prerrogativa, pode-se pensar em um redesign, ou seja, em um design que parte de seu contexto, no sentido do jeito do design, defendido por Latour (2008). No momento em que esta perspectiva for adotada pelo designer, criarse-á a possibilidade de uma base projetual que incorpora a realidade social em seus detalhes, abordando aquilo que é projetado sob uma dimensão mais completa.

Em especial, quando o objeto de design em questão é uma ferramenta ou um instrumento utilizado com um propósito específico (uma tarefa), a compreensão e aplicação da técnica em seu projeto (ou "reprojeto"), pode exigir do designer um cuidado duplo. Duplo, pois o fazer e a técnica se manifestam, neste caso, em dois níveis: o nível da pessoa-designer, que projeta o objeto, decidindo através de seus posicionamentos e necessidades como este deve ser configurado, bem como suas características materiais e imateriais; e o nível da pessoa-usuário, que se utilizará do produto criado para exercer sua ação sobre o mundo.

Nessa situação, a compreensão por parte do designer da tarefa executada pelo usuário é de extrema importância, uma vez que se relaciona diretamente com o propósito do objeto em questão, seja este propósito qual for (simbólico, funcional, estético, etc.). Por esta razão, a fim de imergir na tarefa sob o ponto de vista do usuário (aquele que se utiliza do objeto projetado com determinada propriedade e com determinada perspectiva), o designer, assim como o antropólogo, deve, na tarefa, "estranhar aquilo que the é familiar, e se familiarizar com aquilo que the é estranho", pondo de lado seus preconceitos e se familiarizando com as necessidades de projeto daquele objeto para aquele usuário, mesmo que estas questões sejam a priori estranhas. $O$ designer também deve ter em mente que sua perspectiva sobre o objeto é apenas uma categoria de análise, uma abstração, estando sujeita, portanto, ao perigo da abstração da técnica descrito por Lévy. 
Quando o autor descreve as dimensões politicas e culturais da técnica, bem como os perigos de sua abstração, seus conceitos vão ao encontro da concepção apresentada por Sennett $\left(2013\right.$, p. 149) ${ }^{9}$ em relação às pessoas que desenvolvem altas habilidades manuais. Para elas, segundo este, a técnica está intimamente ligada à expressão. Isso se dá, para Sennett, porque o resultado da aplicação daquela técnica refletirá de algum modo no próprio indivíduo em sua produção, e também porque a técnica empregada com as mãos é necessariamente desenvolvida por este mesmo indivíduo, que coloca um pouco de si em cada detalhe técnico. Nesse sentido, a técnica em si é uma forma de expressão do eu, refletindo-se naquilo que é produzido por meio da interação das mãos e do objeto. Por essa razão, cabe ao designer desconstruir o objeto projetado em múltiplas dimensões de análise, complexificandoo, a fim de incorporar em seu redesign não uma opinião pessoal, perdida no tempo e no espaço, mas, ao contrário, adaptar pequenos detalhes técnicos frente a questões problematizadas dentro de um contexto específico.

\section{REFERÊNCIAS}

LATOUR, Bruno. "A cautious Prometheus? A few steps toward a philosophy of design (with special attention to Peter Sloterdijk)". Proceedings of the 2008 Annual International Conference of the Design History Society. Falmouth: e-book Universal Publisher, 2008.

. Jamais fomos modernos: ensaio de antropologia. Tradução de Carlos Irineu da Costa. Rio de Janeiro: Editora 34, 1994.

LÉVY, Pierre. As tecnologias da inteligência: o futuro do pensamento na era da informática. Tradução de Carlos Irineu da Costa. Rio de Janeiro: Editora 34, 1993.

PIMENTEL, Mariano; FUKS, Hugo (orgs.). Sistemas colaborativos. Elsevier: São Paulo, 2012.

SENNET, Richard. O artífice. Tradução de Clóvis Marques. 4 ed. Rio de Janeiro: Record, 2013.

\footnotetext{
${ }^{9} \mathrm{O}$ autor discute a cultura material, abordando a técnica como uma questão cultural, e não maquinal (Sennett, 2013, p. 19).
} 